\title{
Application of self-made rubber drainage strip in the operation of giant lipoma
}

Ping Shao ${ }^{1}$ and Qing Chen ${ }^{1}$

${ }^{1}$ Cheng Fei Hospital

February 11, 2022

\begin{abstract}
Lipoma is a common benign soft tissue tumor. we report a 33-year-old patient with a giant lipoma in the left scapular region. We placed a self-made rubber drainage strip during the operation to control exudate, which is effective in improving incision effusion and worthy of clinical promotion.

Application of self-made rubber drainage strip in the operation of giant lipoma

Ping Shao, Qing Chen

Department of General Surgery, Cheng Fei Hospital, Chengdu 650091, Sichuan Province, China

Correspondence Qing Chen, Department of General Surgery, Cheng Fei Hospital, Chengdu, Sichuan, China. Email:chenqing4635@163.com

Funding information None

CONFLICTS OF INTEREST There are no conflicts of interest to declare.

AUTHOR CONTRIBUTIONS PS wrote the manuscript; QC drafted the initial manuscript.

CONSENT The written informed consent was obtained from the patient for publication of this manuscript.

DATA AVAILABILITY STATEMENT Data sharing is not applicable to this article as no new data were created or analyzed in this study.

ORCID number: Ping Shao (https://orcid.org/0000-0002-2793-831X); Qing Chen (https://orcid.org/0000-0002-8119-9116).

\section{Abstract}

Lipoma is a common benign soft tissue tumor. Giant lipoma ${ }^{1}$ is generally defined as more than $10 \mathrm{~cm}$ in length or more than $1000 \mathrm{~g}$ in weight. we report a 33-year-old patient with a giant lipoma in the left scapular region. We placed a self-made rubber drainage strip during the operation to control exudate, which is effective in improving incision effusion and worthy of clinical promotion.
\end{abstract}

KEY WORDS: Lipoma; Drainage; Rubber strip

\section{CASE DESCRIPTION}

A 33-year-old man was admitted to our department with complaint of founding a mass in the left scapular region and gradually increased for 2 years, accompanied by discomfort in the supine position. The preoperative imaging examination showed a giant lipoma with a size of about $10.0 \mathrm{~cm} \times 8.7 \mathrm{~cm} \times 1.6 \mathrm{~cm}$. Subsequently, surgical resection was performed. During the operation, we made a transverse fusiform incision on the mass 
surface and placed a self-made rubber drainage strip before the incision was closed. The rubber drainage strip took from a single-use sterile rubber surgical glove. We pulled out the rubber drainage strip on the second day after the operation. The sutures were removed 12 days postoperatively and the incision healed well.

Surgical resection of giant lipoma is most appropriate treatment ${ }^{2}$ and not complicated, however,preventing post-surgical complications (the wound fluid or surgical site infection) is of great importance. Due to the relatively large lacuna and unavoidable exudation left after the operation of the giant lipoma, application of an appropriate wound drainage is necessary. We used a self-made rubber drainage strip, which could decrease the wound fluid and surgical site infection after the giant lipoma resection, worthy of clinical promotion.

\section{REFERENCES}

1. Sanchez MR, Golomb FM, Moy JA, Potozkin JR. Giant lipoma: case report and review of the literature. J Am Acad Dermatol. 1993;28(2 Pt 1): 266-268.

2. Litchinko A, Cherbanyk F, Menth M, Egger B. Giant gluteal lipoma surgical management. BMJ Case Rep . 2019;12(8): e229842.
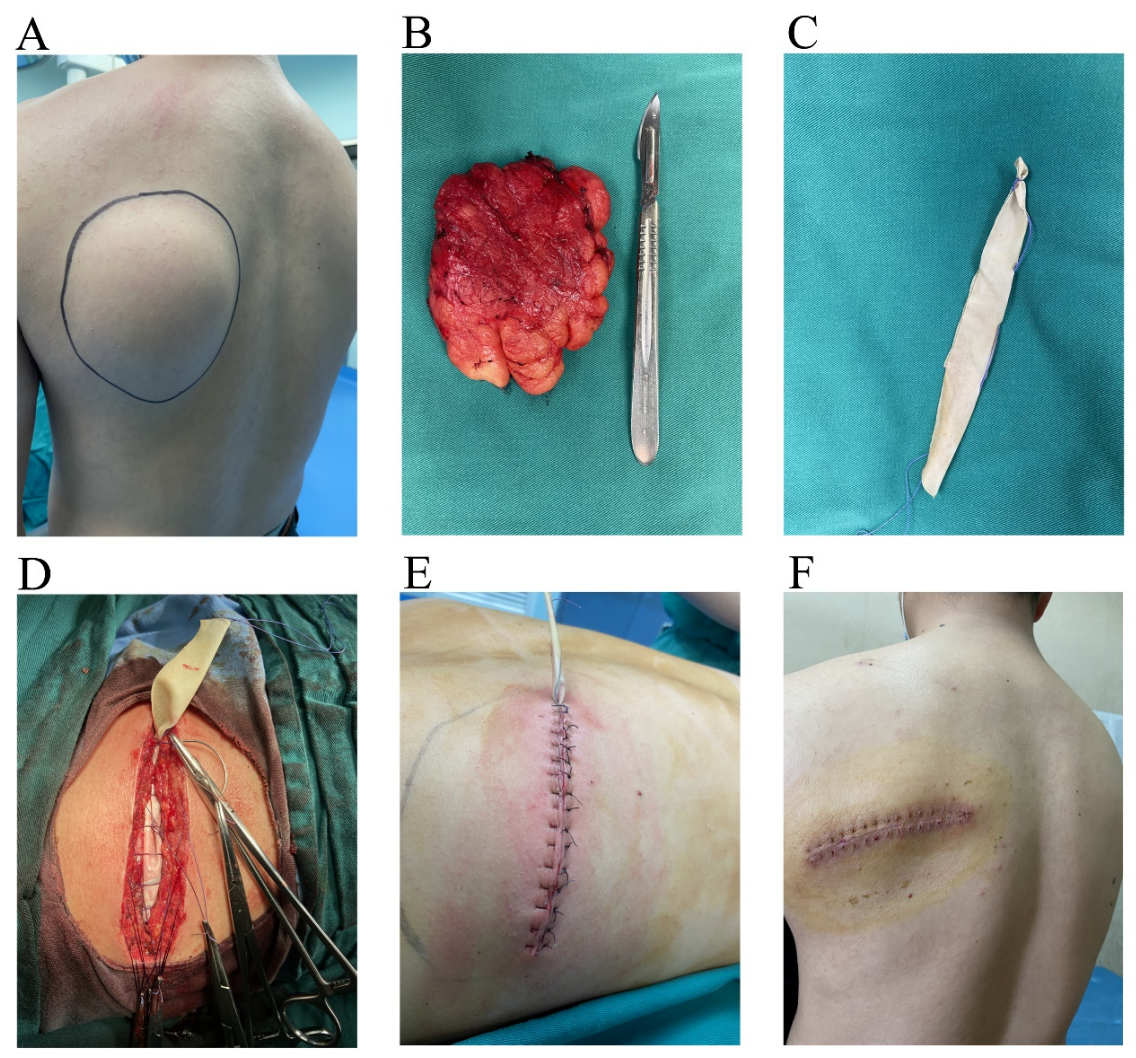

Figure 1. A: A giant mass in the left scapular region. B: A lipoma with a size of about $10.0 \mathrm{~cm} \times 8.7 \mathrm{~cm} \times 1.6 \mathrm{~cm}$. C: A self-made rubber drainage strip. D: Placing a self-made rubber drainage strip before closing the incision. E: Interrupted vertical mattress valgus suture was completed. F: The sutures were removed 12 days postoperatively and the incision healed well. 

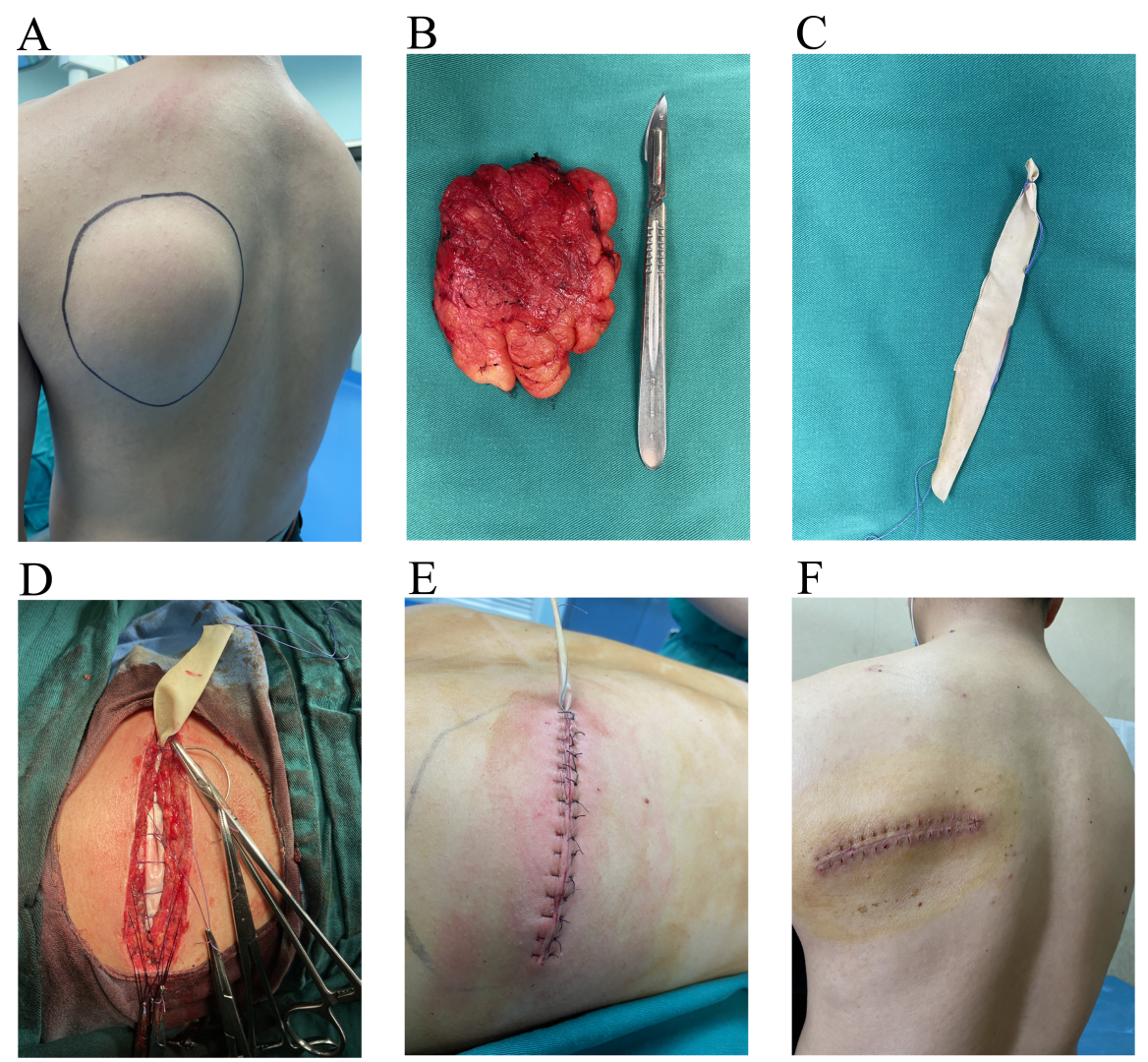

E
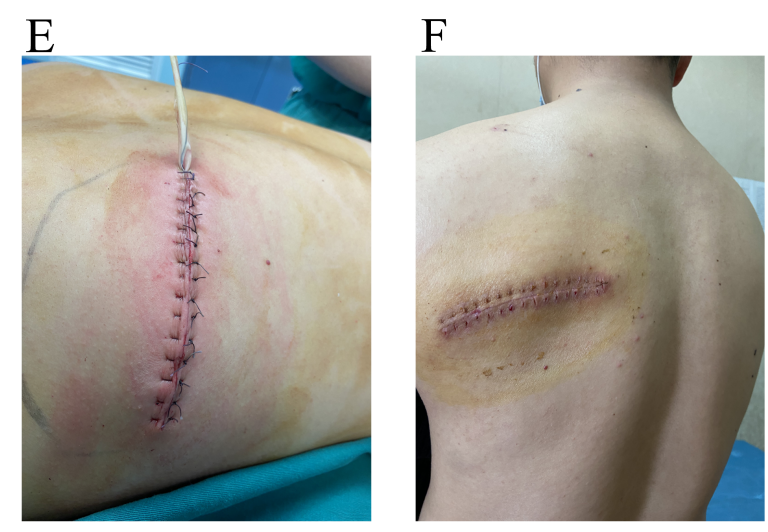